\title{
The Asia Pacific Consensus Statement on Laparoscopic Liver Resection for Hepatocellular Carcinoma: A Report from the 7th Asia-Pacific Primary Liver Cancer Expert Meeting Held in Hong Kong
}

\author{
Tan To Cheung $^{a}$ Ho-Seong Han ${ }^{b}$ Wong Hoi She ${ }^{a}$ Kuo-Hsin Chen ${ }^{c}$ \\ Pierce K.H. Chow ${ }^{d}$ Boon Koon Yoong ${ }^{\text {e }}$ Kit Fai Lee $^{f}$ Shoji Kubog \\ Chung Ngai Tang ${ }^{\text {h }}$ Go Wakabayashi ${ }^{i}$ \\ a Department of Surgery, The University of Hong Kong, Queen Mary Hospital, Hong Kong \\ (SAR), China; ${ }^{b}$ Department of Surgery, Seoul National University Bundang Hospital, Seoul \\ National College of Medicine, Seoul, South Korea; ${ }^{C}$ Department of Surgery, Far-Eastern \\ Memorial Hospital, New Taipei City, Taiwan, China; ${ }^{d}$ National Cancer Center, Singapore,

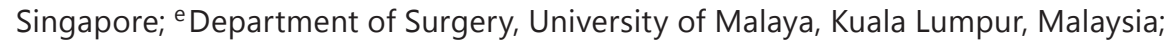 \\ fDepartment of Surgery, The Chinese University of Hong Kong, Prince of Wales Hospital, \\ Hong Kong (SAR), China; ${ }^{9}$ Department of Hepato-Biliary-Pancreatic Surgery, Osaka City \\ University Graduate School of Medicine, Osaka, Japan; ${ }^{\text {h }}$ Department of Surgery, Pamela \\ Youde Nethersole Eastern Hospital, Hong Kong (SAR), China; 'Department of Surgery, Ageo \\ Central General Hospital, Ageo, Japan
}

\section{Keywords}

3D laparoscopy · Cirrhosis · Evidence $\cdot$ Hepatocellular carcinoma $\cdot$ International consensus conference $\cdot$ International consensus guidelines $\cdot$ Hepatectomy $\cdot$ Liver resection

\begin{abstract}
Background: Laparoscopic liver resection has been gaining momentum, and it has become an accepted practice after the two international consensus conferences where experts worked up guidelines to standardize this approach and improve its safety. However, most laparoscopic hepatectomies were performed in patients with liver metastases. The concurrent presence of liver cirrhosis with hepatocellular carcinoma (HCC) poses a great challenge to clinicians trying to establish a routine use of laparoscopic liver resection for HCC. Summary: The first Asia Pacific consensus meeting on laparoscopic liver resection for HCC was held in July 2016 in Hong Kong. A group of expert liver surgeons with experience in both open and laparoscopic hepatectomy for HCC convened to formulate recommendations on the role and perspective of laparoscopic liver resection for primary liver cancer. The recommendations con-
\end{abstract}




\section{Liver Cancer}

solidate the most recent evidence pertaining to laparoscopic hepatectomy together with the latest thinking of practicing clinicians involved in laparoscopic hepatectomy, and give detailed guidance on how to deploy the treatment effectively for patients in need. Key Message: The panel of experts gathered evidence and produced recommendations providing guidance on the safe practice of laparoscopic hepatectomy for patients with HCC and cirrhosis. The inherent advantage of the laparoscopic approach may result in less blood loss if the procedure is performed in experienced centers. The laparoscopic approach to minor hepatectomy, particularly left lateral sectionectomy, is a preferred practice for HCC at experienced centers. Laparoscopic major liver resection for HCC remains a technically challenging operation, and it should be carried out in centers of excellence. There is emerging evidence that laparoscopic liver resection produces a better oncological outcome for HCC when compared with radiofrequency ablation, particularly when the lesions are peripherally located. Augmented features in laparoscopic liver resection, including indocyanine green fluorescence, 3D laparoscopy, and robot, will become important tools of surgical treatment in the near future. A combination of all of these features will enhance the experience of the surgeons, which may translate into better surgical outcomes. This is the first consensus workforce on laparoscopic liver resection for HCC, which is a unique condition that occurs in the Asia Pacific region.

(C) 2017 S. Karger AG, Base

\section{Introduction}

Hepatocellular carcinoma (HCC) is the sixth most common cancer worldwide [1]. It has a very high prevalence in the Asia Pacific region because of the high prevalence of chronic hepatitis B and C, and it is one of the top cancer killers in the region. Unfortunately, patients with HCC usually present with underlying liver cirrhosis, which is a major adverse factor for liver resection [2-4].

Laparoscopic liver resection is becoming an accepted approach for liver cancers [5, 6], particularly on liver metastases [7-11], after two international consensus conferences held in Louisville in 2008 [12] and Morioka in 2014 [13]. To date, there has been no randomized controlled trial published. However, the number of cases published has been rapidly increasing to more than 9,000. Many of these cases were reported in the form of case series [14-17], case control study [18-28], or systematic review and meta-analysis [5, 6, 29-32]. Many specialized centers of liver cancer management are now entering the exploration and assessment phase. In HCC patients with underlying liver cirrhosis, laparoscopic liver resection is difficult because of the presence of portal hypertension and thus a high bleeding tendency which renders parenchymal transection difficult $[15,28,33]$. Safe performance of the operation calls for ample experience [34-36].

The first Asia Pacific consensus meeting for HCC was held in conjunction with the 7th Asia-Pacific Primary Liver Cancer Expert Meeting in Hong Kong in order to achieve the goals of defining the role of laparoscopic liver resection in HCC management and developing recommendations and guidelines.

The organizing committee formulated 10 questions to collect evidence on issues on benefits and techniques of laparoscopic liver resection for HCC (Table 1).

In a series of meetings held on 8-10 July, 2016, a group of expert liver surgeons with experience in both open and laparoscopic hepatectomy for HCC convened to formulate recommendations on the role and perspective of laparoscopic liver resection for primary liver cancer.

A search of the literature in English was performed through MEDLINE, Embase, and Cochrane Library for articles on laparoscopic liver resection published in the period from 
Cheung et al.: Consensus on Laparoscopic Hepatectomy for HCC

Table 1. Session topics on laparoscopic resection for primary liver cancer

1 Evidence on laparoscopic liver resection for HCC

2 Laparoscopic liver resection for small HCCs: radiofrequency ablation vs. laparoscopic hepatectomy

3 Laparoscopic liver resection in patients with marginal liver function

4 Laparoscopic liver resection in patients with portal vein involvement

5 Laparoscopic liver resection learning curve issues

6 Robotic liver resection for HCC

7 The use of augmented techniques for laparoscopic hepatectomy (indocyanine green fluorescence and 3D systems)

8 The use of hemostatic agents in patients with cirrhosis

9 Laparoscopic approach to treating HCC in difficult locations

1991 to July 2016. Consensus statements were developed by group members designated before the meetings. The statements were circulated among the members and modified according to feedback. At the meeting, each statement was assessed on a five-point Likert Scale $(1$ - Accept completely, 2 - Accept with some reservations, 3 - Accept with major revisions, 4 - Reject with reservations, 5 - Reject completely). Votes on the statements were recorded instantly by a secretary of the meeting. Agreement by $80 \%$ of the group to accept completely a statement was defined as consensus on that statement. A statement on which consensus was not achieved was modified and put to the vote again until consensus was reached. Finally, the group evaluated each statement's level of evidence as per the 2011 Oxford criteria [37]. In the following, each statement's level of evidence is shown.

\section{Consensus Recommendations}

Evidence on Laparoscopic Liver Resection for HCC

1 Laparoscopic minor liver resection for early stage ( $\leq \mathrm{T} 2)$ HCC located in segment 2, 3, 4b, 5 , or 6 is a safe option in centers with experience. [Level 3 evidence]

2 Laparoscopic minor liver resection in difficult locations (1, 4a, 7, 8 (difficulty score intermediate grade or above)) should be performed in centers of excellence. [Level 3 evidence] 3 Laparoscopic major hepatectomy (more than 3 segments) is an operation with high complexity and should be carried out in centers of excellence. Further evidence will support the development of this practice. [Level 3 evidence]

The Panel has discussed the definition of center of excellence for laparoscopic liver resection in order to ensure good practice and patient safety. A center of excellence for laparoscopic liver resection should consist of a dedicated multidisciplinary liver team that includes surgeons, hepatologists, radiologists, oncologists, anesthesiologists, and nurses to ensure every patient receives the best treatment option for his/her condition. The center performs at least 30 laparoscopic liver resections per year. Surgeons must have performed at least 100 laparoscopic liver resections on their own over a lifetime, and at least 20 cases per year.

There is more evidence on the short- and long-term results of laparoscopic minor liver resection for HCC $[18,28,38-45]$. It has been consistently observed that the laparoscopic approach to minor liver resection is associated with less blood loss [26, 45-48], less blood transfusion [26], and shorter hospital stay [22, 25, 26, 46, 48]. It has been proven that the long-term results of this treatment modality are not inferior to those of the open approach [5, $24,46,48,49]$. One recent study showed that laparoscopic minor hepatectomy was associated with a better survival outcome [28]. In the long run, the benefits of the no-touch tech- 


\section{Liver Cancer}

\begin{tabular}{l|l}
\hline Liver Cancer 2018;7:28-39 \\
\hline DOI: 10.1159/000481834 & $\begin{array}{l}\text { @ 2017 S. Karger AG, Basel } \\
\text { www.karger.com/lic }\end{array}$ \\
\hline
\end{tabular}

Cheung et al.: Consensus on Laparoscopic Hepatectomy for HCC

nique, less blood loss, and less transfusion could be reflected by better overall and diseasefree survival.

On the other hand, the evidence for laparoscopic major hepatectomy for HCC is less strong as this surgery remains a technically challenging procedure, particularly in patients with liver cirrhosis [50]. Worldwide, the number of surgeons who can perform this procedure proficiently is relatively small, when compared with open liver resection [51]. More evidence is needed to support the growth of laparoscopic major liver resection for HCC patients.

Patient Selection for Laparoscopic Hepatectomy for HCC

Liver Function Evaluation

4 Selection of patients for laparoscopic liver resection for HCC in terms of liver function should be the same as in open liver resection. [Level 3 evidence]

5 Laparoscopic liver resection for HCC is reported to be better tolerated in patients with marginal liver function. [Level 3 evidence]

Selection of HCC patients for laparoscopic liver resection should largely follow the safety principles used in open hepatectomy $[4,52]$. In many studies, HCC patients were considered suitable for laparoscopic hepatectomy if they could tolerate general anesthesia, had Child A liver function, and had a suitable platelet count $\left(>40 \times 10^{9} / \mathrm{L}\right.$ for minor hepatectomy, $>80 \times$ $10^{9} / \mathrm{L}$ for major hepatectomy) $[46,53,54]$. Patients were not considered suitable if they had decompensated Child B or Child C liver cirrhosis [52]. In Asia, preoperative indocyanine green retention rate at $15 \mathrm{~min}$ after injection is given emphasis $[55,56]$. Studies have shown that some patients with Child A cirrhosis may not tolerate hepatectomy well, while some patients with Child B liver cirrhosis can perform well after liver resection $[53,57,58]$. The acceptable indocyanine green retention rates for major hepatectomy range from 14.4 to $20 \%$, depending on the experience of individual centers [59-65].

Tumor Size Consideration

6 Laparoscopic liver resection for HCCs $\leq 5 \mathrm{~cm}$ in favorable locations is a safe procedure in centers with experience. [Level 3 evidence]

7 Laparoscopic liver resection for HCCs $>5 \mathrm{~cm}$ should only be carried out in centers of excellence. [Level 4 evidence]

8 Laparoscopic liver resection is not usually indicated for HCCs $>10 \mathrm{~cm}$. Patients should be carefully selected, and the resection should be performed only in centers of excellence. [Level 4 evidence]

In most of the reviews in the literature, the median tumor size was smaller than $5 \mathrm{~cm}$ in laparoscopic liver resection for HCC $[66,67]$. Most surgeons performing laparoscopic liver resection follow the rules recommended by the Louisville statement 2008 . According to the statement, the most favorable indication for laparoscopic resection is a solitary lesion, $5 \mathrm{~cm}$ or smaller, located in one of the peripheral liver segments 2-6 [12]. The panel considered that laparoscopic resection of tumors larger than $5 \mathrm{~cm}$ are only possible in centers of excellence because these lesions will raise concerns about oncological compromise, margin clearance, and risk of rupture during manipulation $[12,66,68]$. Likewise, for tumors measuring about $10 \mathrm{~cm}$, there will be the consideration of specimen delivery - a considerably bigger wound will need to be made. However, the panel also took into consideration the fact that experience and proficiency in laparoscopic liver resection for HCC are growing, and many centers have successfully performed laparoscopic liver resection in more difficult locations [69] and on bigger tumors [70-72], and thus suggested that laparoscopic resection for these difficult cases should only be performed in centers of excellence with careful patient selection. 
Tumor Location, Anatomical Resection versus Nonanatomical Resection

9 Laparoscopic wedge liver resection for small $(<2 \mathrm{~cm})$ peripheral HCCs is the preferable surgical option. [Level 3 evidence]

10 Laparoscopic anatomical liver resection (including monosegmentectomy and subsegmentectomy) is generally recommended for patients with HCC. [Level 3 evidence]

Anatomical resection has always been advocated by many surgeons in the hope of producing better oncological outcomes [73-76] (reference included).

On the other hand, in the management of HCC with liver cirrhosis, liver preservation is an important concept in preventing posthepatectomy liver failure. Anatomical monosegmentectomy seems to be a good option to achieve maximal oncological clearance and liver function preservation. However, anatomical liver resection requires more complex surgical skills [77]. The transection plane usually lies along vital and vulnerable anatomical structures such as the portal vein, hepatic veins, and bile ducts. Anatomical monosegmentectomy in laparoscopic surgery is highly complex and should only be performed by surgeons at centers of excellence. Many factors affect the recurrence of HCC, including tumor size, presence of microvascular invasion, Edmondson grading of the cancer cells, and width of surgical resection margin [78-80]. Anatomical resection cannot alter these factors and should be performed only when it is technically feasible and when the function of the remnant liver would allow. As it is usually more complicated than a wedge resection, an anatomical resection is likely to have a higher difficulty grade, a longer operation time, more blood loss, and a higher complication rate, especially if the tumor is located at the periphery of the liver. A smart clinical decision has to be made in the field.

The Role of Laparoscopic Liver Resection versus Radiofrequency Ablation

11 The effectiveness of laparoscopic liver resection is comparable to that of radiofrequency ablation, with a lower recurrence rate in patients with small HCCs. [Level 3 evidence]

12 Laparoscopic liver resection minimizes the risk of local intrahepatic recurrence, which can result from preexisting microscopic tumor foci or tumor dissemination by radiofrequency ablation. [Level 3 evidence]

13 Laparoscopic liver resection is favored in patients with peripheral HCCs in segments 2-6, and/or when a histological assessment is desirable. [Level 4 evidence]

Some case-control series showed that laparoscopic liver resection of smaller HCCs had favorable midterm outcomes [28, 81]. In studies comparing open liver resection with radiofrequency ablation in treating tumors smaller than $2 \mathrm{~cm}$, the two modalities resulted in similar overall survival [82-85], but disease-free survival after open liver resection was better [81, 85-87]. Theoretically, hepatectomy removes all tumor cells from the liver and reduces the chance of intrahepatic recurrence from the same tumor. For tumors larger than $3 \mathrm{~cm}$, liver resection was shown to produce better overall survival [88]. The advantages of radiofrequency ablation over open liver resection include less invasiveness, shorter operation time, less blood loss, and faster recovery [87]. Laparoscopic liver resection has all these advantages and also better oncological clearance $[28,89]$. In actual practice, radiofrequency ablation can still be an easier option if the HCC is small and in a difficult location.

HCC with Portal Vein Invasion

The panel has discussed the issue of laparoscopic liver resection with portal vein invasion. However, as the evidence on this area is still limited, we did not conclude to make a recommendation.

HCC with portal vein invasion is associated with poorer prognosis [90-92]. Liver resection provides better survival when compared with nonsurgical treatments such as transarterial chemoembolization and targeted therapy $[93,94]$. Most of the evidence arose in studies of 


\section{Liver Cancer}

\begin{tabular}{l|l}
\hline Liver Cancer 2018;7:28-39 \\
\hline DOI: 10.1159/000481834 & $\begin{array}{l}\text { @ 2017 S. Karger AG, Basel } \\
\text { www.karger.com/lic }\end{array}$ \\
\hline
\end{tabular}

Cheung et al.: Consensus on Laparoscopic Hepatectomy for HCC

open liver resection. The feasibility of laparoscopic liver resection for HCC with portal vein resection has been reported [95], but long-term results are still lacking. The panel agreed that laparoscopic liver resection for HCC with portal vein invasion is feasible if the tumor thrombus involves only the left lateral section branches. In selected centers, laparoscopic hepatectomy with portal vein reconstruction is possible if the tumor involves only Vp3 and Vp4. Favorable long-term outcomes are needed to validate this type of procedure.

Learning Curve of Laparoscopic Liver Resection for HCC

14 The difficulty scoring system is useful for evaluation of the operation difficulty of laparoscopic liver resection for HCC. [Level 3 evidence]

15 Laparoscopic liver resection for HCC classified into high and intermediate difficulty should be performed in centers of excellence. [Level 4 evidence]

16 It is necessary to gradually improve skills according to the difficulty level. [Level 4 evidence]

The safety and continuity of laparoscopic liver resection can only be ensured by learning and education. A difficulty score system was proposed in the Morioka consensus meeting in 2014, which categorized laparoscopic liver resection into three levels: easy, intermediate, and expert $[13,96]$. Factors affecting the difficulty include tumor location, tumor size, presence of cirrhosis, and proximity to major vessels. This grading system has been validated by several centers [97-99]. It is generally agreed that the system provides a good reflection of the complexity of the surgery. The difficulty scale gives a good guideline on how to learn laparoscopic liver resection. It helps to prevent mismatch of experience and complexity, which is a main reason for surgical misfortune.

Gradual improvement of skill comes in accumulating experience by climbing up the difficulty scale ladder $[35,36,51]$.

The Use of Augmented Laparoscopic Technology, Robots, and Other Adjuncts in

Hepatectomy

Indocyanine Green Fluorescence and 3D Laparoscopy

17 Indocyanine green fluorescence is a promising technology that may have a value on laparoscopic liver resection for HCC. [Level 4 evidence]

18 3D laparoscopy is a useful adjunct that may enhance surgeons' performance in laparoscopic liver resection for HCC. [Level 4 evidence]

Technological advancement is an irreversible evolution that allows progression of surgical procedures. The use of high-definition video cameras and display units is a major breakthrough in laparoscopic surgery. Amplification of the visual field makes meticulous dissection possible $[100,101]$. In recent years, the development of the 3D laparoscopic system has become very mature. Studies have shown that surgeons perform better in a 3D laparoscopic environment where better spatial recognition is observed [102]. It improves hand-eye coordination. As a result, complex laparoscopic work like suturing takes less time [101]. Laparoscopic liver resection can also be helped by the use of indocyanine green fluorescence, which has the advantages of real time illumination of occult lesions $[103,104]$, revealing the surgical margins [105], identifying anatomical landmarks of the liver [106$110]$, and showing a more precise pathology in surgical specimens $[111,112]$. These are relatively new technologies, and it may be difficult to demonstrate a statistically significant clinical difference with their use. Nonetheless, these technologies are becoming common practice, and as the prices of these units are going down, they will become standard equipment very soon. 
Robotic-Assisted Hepatectomy

19 The feasibility and safety of robotic minor/major resection for HCC have been demonstrated with trained surgeons and appropriate patient selection. [Level 3 evidence]

20 The robotic approach may have a role in treating HCC in difficult segments and bring about a higher rate of major hepatectomy in some centers. [Level 3 evidence]

21 Comparative studies have not shown any significant differences in the short-term outcomes brought by the laparoscopic approach [Level 3 evidence] and evidence is needed to define its long-term oncological outcomes for HCC

The use of robots has become another main stream in laparoscopic surgery. Hospitals with robotic surgical facilities have made good use of them and favorable outcomes have been observed. Studies have shown that pure laparoscopic hepatectomy and robotic surgery have comparable outcomes [113-117]. The learning curve of robotic surgery may be shorter, but the ease of entry may be more restricted since the equipment is not widely available. The panel agreed that robotic surgery may enhance the feasibility of the laparoscopic approach for HCC.

The Use of Hemostatic Agents

22 Further evidence is required to support the use of hemostatic agents for laparoscopic liver resection for HCC with cirrhosis. [Level 4 evidence]

The use of hemostatic agents after completion of liver transection is a common practice in laparoscopic liver resection. This may give the operating surgeons an additional sense of security, particularly if the liver is cirrhotic $[118,119]$. The panel agreed that so far there is inadequate evidence that the use of hemostatic agents will prevent secondary bleeding after laparoscopic liver resection for HCC. There is very little such evidence in open liver resection either [120-122]. The key to prevent re-bleeding is adequate hemostasis during laparoscopy. During liver transection, the central venous pressure is maintained at a low level $(<5 \mathrm{~mm} \mathrm{Hg})$, if possible, by strict control of intravenous fluid administration to reduce venous bleeding from the liver. The patient should also be placed in the reversed Trendelenburg position around $15-30^{\circ}$. An additional tip is to check the final hemostasis at a reduced pneumoperitoneal pressure and an adequate systolic blood pressure before wound closure.

\section{Summary}

In this consensus meeting, the expert panel made 22 recommendations on the position of laparoscopic hepatectomy for HCC. These recommendations consolidate the latest evidence pertaining to HCC treatment and provide detailed guidelines on how to deploy laparoscopic liver resection effectively for this group of patients. Although the panel had performed an extensive review on this topic, most of the evidence gathered was Level 3 and Level 4. Currently, there is no Level 1 and 2 evidence for this area, and further high-quality research is needed to conclude the growth of laparoscopic liver resection. Distinct from the Louisville statement 2008 and the Morioka consensus 2014, our current recommendations focus mainly on the treatment of HCC, a disease often accompanied by liver cirrhosis. These recommendations have arisen from combining evidence gathered from new studies and our experience in treating our patients with positive outcomes. The recommendations are meant to sustain the benefits of laparoscopic liver resection for HCC.

\section{Disclosure Statement}

The authors declare no conflicts of interest. 


\section{References}

1 Ferlay J, Shin HR, Bray F, Forman D, Mathers C, Parkin DM: Estimates of worldwide burden of cancer in 2008: GLOBOCAN 2008. Int J Cancer 2010;127:2893-2917.

2 Nagasue N, Kohno H, Tachibana M, Yamanoi A, Ohmori H, El-Assal ON: Prognostic factors after hepatic resection for hepatocellular carcinoma associated with Child-Turcotte class B and C cirrhosis. Ann Surg 1999; 229:84-90.

3 Ueno S, Tanabe G, Nuruki K, Oketani M, Komorizono Y, Hokotate H, et al: Prognosis of hepatocellular carcinoma associated with Child class B and C cirrhosis in relation to treatment: a multivariate analysis of 411 patients at a single center. J Hepatobiliary Pancreat Surg 2002;9:469-477.

4 Fan ST, Mau Lo C, Poon RT, Yeung C, Leung Liu C, Yuen WK, et al: Continuous improvement of survival outcomes of resection of hepatocellular carcinoma: a 20-year experience. Ann Surg 2011;253:745-758.

5 Chen J, Bai T, Zhang Y, Xie ZB, Wang XB, Wu FX, et al: The safety and efficacy of laparoscopic and open hepatectomy in hepatocellular carcinoma patients with liver cirrhosis: a systematic review. Int J Clin Exp Med 2015;8:20679-20689.

6 Morise Z, Ciria R, Cherqui D, Chen KH, Belli G, Wakabayashi G: Can we expand the indications for laparoscopic liver resection? A systematic review and meta-analysis of laparoscopic liver resection for patients with hepatocellular carcinoma and chronic liver disease. J Hepatobiliary Pancreat Sci 2015;22:342-352.

7 Allard MA, Cunha AS, Gayet B, Adam R, Goere D, Bachellier P, et al: Early and long-term oncological outcomes after laparoscopic resection for colorectal liver metastases: a propensity score-based analysis. Ann Surg 2015; 262:794-802.

8 Ratti F, Catena M, Di Palo S, Staudacher C, Aldrighetti L: Laparoscopic approach for primary colorectal cancer improves outcome of patients undergoing combined open hepatic resection for liver metastases. World J Surg 2015;39:2573-2582.

9 Beppu T, Wakabayashi G, Hasegawa K, Gotohda N, Mizuguchi T, Takahashi Y, et al: Long-term and perioperative outcomes of laparoscopic versus open liver resection for colorectal liver metastases with propensity score matching: a multi-institutional Japanese study. J Hepatobiliary Pancreat Sci 2015;22:711-720.

10 Fretland AA, Kazaryan AM, Bjornbeth BA, Flatmark K, Andersen MH, Tonnessen TI, et al: Open versus laparoscopic liver resection for colorectal liver metastases (the Oslo-CoMet Study): study protocol for a randomized controlled trial. Trials 2015;16:73.

11 Hasegawa Y, Nitta H, Sasaki A, Takahara T, Itabashi H, Katagiri H, et al: Long-term outcomes of laparoscopic versus open liver resection for liver metastases from colorectal cancer: a comparative analysis of 168 consecutive cases at a single center. Surgery 2015;157:1065-1072.

12 Buell JF, Cherqui D, Geller DA, O’Rourke N, Iannitti D, Dagher I, et al: The international position on laparoscopic liver surgery: The Louisville Statement, 2008. Ann Surg 2009;250:825-830.

13 Wakabayashi G, Cherqui D, Geller DA, Buell JF, Kaneko H, Han HS, et al: Recommendations for laparoscopic liver resection: a report from the second international consensus conference held in Morioka. Ann Surg 2015; 261:619-629.

14 Hwang DW, Han HS, Yoon YS, Cho JY, Kwon Y, Kim JH, et al: Laparoscopic major liver resection in Korea: a multicenter study. J Hepatobiliary Pancreat Sci 2013;20:125-130.

15 Shehta A, Han HS, Yoon YS, Cho JY, Choi Y: Laparoscopic liver resection for hepatocellular carcinoma in cirrhotic patients: 10-year single-center experience. Surg Endosc 2016;30:638-648.

16 Komatsu S, Brustia R, Goumard C, Sepulveda A, Perdigao F, Soubrane O, et al: Clinical impact of laparoscopic hepatectomy: technical and oncological viewpoints. Surg Endosc 2017;31:1442-1450.

17 Goh BK, Chan CY, Lee SY, Lee VT, Cheow PC, Chow PK, et al: Laparoscopic liver resection for tumors in the left lateral liver section. JSLS 2016;20:e2015.00112.

18 Belli G, Limongelli P, Fantini C, D’Agostino A, Cioffi L, Belli A, et al: Laparoscopic and open treatment of hepatocellular carcinoma in patients with cirrhosis. Br J Surg 2009;96:1041-1048.

19 Truant S, Bouras AF, Hebbar M, Boleslawski E, Fromont G, Dharancy S, et al: Laparoscopic resection vs. open liver resection for peripheral hepatocellular carcinoma in patients with chronic liver disease: a case-matched study. Surg Endosc 2011;25:3668-3677.

20 Kanazawa A, Tsukamoto T, Shimizu S, Kodai S, Yamazoe S, Yamamoto S, et al: Impact of laparoscopic liver resection for hepatocellular carcinoma with F4-liver cirrhosis. Surg Endosc 2013;27:2592-2597.

21 Memeo R, de'Angelis N, Compagnon P, Salloum C, Cherqui D, Laurent A, et al: Laparoscopic vs. open liver resection for hepatocellular carcinoma of cirrhotic liver: a case-control study. World J Surg 2014;38:29192926.

22 Siniscalchi A, Ercolani G, Tarozzi G, Gamberini L, Cipolat L, Pinna AD, et al: Laparoscopic versus open liver resection: differences in intraoperative and early postoperative outcome among cirrhotic patients with hepatocellular carcinoma - a retrospective observational study. HPB Surg 2014;2014:871251.

23 Yamashita Y, Ikeda T, Kurihara T, Yoshida Y, Takeishi K, Itoh S, et al: Long-term favorable surgical results of laparoscopic hepatic resection for hepatocellular carcinoma in patients with cirrhosis: a single-center experience over a 10-year period. J Am Coll Surg 2014;219:1117-1123.

24 Luo L, Zou H, Yao Y, Huang X: Laparoscopic versus open hepatectomy for hepatocellular carcinoma: short- and long-term outcomes comparison. Int J Clin Exp Med 2015;8:18772-18778. 
25 Han HS, Shehta A, Ahn S, Yoon YS, Cho JY, Choi Y: Laparoscopic versus open liver resection for hepatocellular carcinoma: case-matched study with propensity score matching. J Hepatol 2015;63:643-650.

26 Untereiner X, Cagnet A, Memeo R, De Blasi V, Tzedakis S, Piardi T, et al: Short-term and middle-term evaluation of laparoscopic hepatectomies compared with open hepatectomies: a propensity score matching analysis. World J Gastrointest Surg 2016;8:643-650.

27 Xiang L, Li J, Chen J, Wang X, Guo P, Fan Y, et al: Prospective cohort study of laparoscopic and open hepatectomy for hepatocellular carcinoma. Br J Surg 2016.

28 Cheung TT, Dai WC, Tsang SH, Chan AC, Chok KS, Chan SC, et al: Pure laparoscopic hepatectomy versus open hepatectomy for hepatocellular carcinoma in 110 patients with liver cirrhosis: a propensity analysis at a single center. Ann Surg 2016;264:612-620.

29 Yin Z, Fan X, Ye H, Yin D, Wang J: Short- and long-term outcomes after laparoscopic and open hepatectomy for hepatocellular carcinoma: a global systematic review and meta-analysis. Ann Surg Oncol 2013;20:1203-1215.

30 Twaij A, Pucher PH, Sodergren MH, Gall T, Darzi A, Jiao LR: Laparoscopic vs open approach to resection of hepatocellular carcinoma in patients with known cirrhosis: systematic review and meta-analysis. World J Gastroenterol 2014;20:8274-8281.

31 Cheung TT, Lo CM: Laparoscopic liver resection for hepatocellular carcinoma in patients with cirrhosis. Hepatobiliary Surg Nutr 2015;4:406-410.

32 Ciria R, Cherqui D, Geller DA, Briceno J, Wakabayashi G: Comparative short-term benefits of laparoscopic liver resection: 9000 cases and climbing. Ann Surg 2016;263:761-777.

33 Worhunsky DJ, Dua MM, Tran TB, Siu B, Poultsides GA, Norton JA, et al: Laparoscopic hepatectomy in cirrhotics: safe if you adjust technique. Surg Endosc 2016;30:4307-4314.

34 Spampinato MG, Arvanitakis M, Puleo F, Mandala L, Quarta G, Baldazzi G: Assessing the learning curve for totally laparoscopic major-complex liver resections: a single hepatobiliary surgeon experience. Surg Laparosc Endosc Percutan Tech 2015;25:e45-e50.

35 Nomi T, Fuks D, Kawaguchi Y, Mal F, Nakajima Y, Gayet B: Learning curve for laparoscopic major hepatectomy. Br J Surg 2015;102:796-804.

36 Lin CW, Tsai TJ, Cheng TY, Wei HK, Hung CF, Chen YY, et al: The learning curve of laparoscopic liver resection after the Louisville statement 2008: will it be more effective and smooth? Surg Endosc 2016;30:2895-2903.

37 Hovick J, Chalmers I, Glasziou P, Greenhalgh T, Heneghan C, Liberati A, Moschetti I, Phillips B, Thornton H, Goddard O, Hodgkinson M: The Oxford 2011 Levels of Evidence. Oxford, Centre for Evidence-Based Medicine, 2011.

38 Sasaki A, Nitta H, Otsuka K, Takahara T, Nishizuka S, Wakabayashi G: Ten-year experience of totally laparoscopic liver resection in a single institution. Br J Surg 2009;96:274-279.

39 Tranchart H, Di Giuro G, Lainas P, Roudie J, Agostini H, Franco D, et al: Laparoscopic resection for hepatocellular carcinoma: a matched-pair comparative study. Surg Endosc 2010;24:1170-1176.

40 Aldrighetti L, Guzzetti E, Pulitano C, Cipriani F, Catena M, Paganelli M, et al: Case-matched analysis of totally laparoscopic versus open liver resection for HCC: short and middle term results. J Surg Oncol 2010;102:82-86.

41 Kim HH, Park EK, Seoung JS, Hur YH, Koh YS, Kim JC, et al: Liver resection for hepatocellular carcinoma: casematched analysis of laparoscopic versus open resection. J Korean Surg Soc 2011;80:412-419.

42 Ker CG, Chen JS, Kuo KK, Chuang SC, Wang SJ, Chang WC, et al: Liver surgery for hepatocellular carcinoma: laparoscopic versus open approach. Int J Hepatol 2011;2011:596792.

43 Lee KF, Chong CN, Wong J, Cheung YS, Wong J, Lai P: Long-term results of laparoscopic hepatectomy versus open hepatectomy for hepatocellular carcinoma: a case-matched analysis. World J Surg 2011;35:2268-2274.

44 Goh BK, Chan CY, Wong JS, Lee SY, Lee VT, Cheow PC, et al: Factors associated with and outcomes of open conversion after laparoscopic minor hepatectomy: initial experience at a single institution. Surg Endosc 2015; 29:2636-2642.

45 Cheung TT, Poon RT, Dai WC, Chok KS, Chan SC, Lo CM: Pure laparoscopic versus open left lateral sectionectomy for hepatocellular carcinoma: a single-center experience. World J Surg 2016;40:198-205.

46 Cheung TT, Poon RT, Yuen WK, Chok KS, Jenkins CR, Chan SC, et al: Long-term survival analysis of pure laparoscopic versus open hepatectomy for hepatocellular carcinoma in patients with cirrhosis: a single-center experience. Ann Surg 2013;257:506-511.

47 Takahara T, Wakabayashi G, Nitta H, Hasegawa Y, Katagiri H, Takeda D, et al: Laparoscopic liver resection for hepatocellular carcinoma with cirrhosis in a single institution. Hepatobiliary Surg Nutr 2015;4:398-405.

48 Takahara T, Wakabayashi G, Beppu T, Aihara A, Hasegawa K, Gotohda N, et al: Long-term and perioperative outcomes of laparoscopic versus open liver resection for hepatocellular carcinoma with propensity score matching: a multi-institutional Japanese study. J Hepatobiliary Pancreat Sci 2015;22:721-727.

49 Jiang X, Liu L, Zhang Q, Jiang Y, Huang J, Zhou H, et al: Laparoscopic versus open hepatectomy for hepatocellular carcinoma: long-term outcomes. J BUON 2016;21:135-141.

50 Komatsu S, Brustia R, Goumard C, Perdigao F, Soubrane O, Scatton O: Laparoscopic versus open major hepatectomy for hepatocellular carcinoma: a matched pair analysis. Surg Endosc 2016;30:1965-1974.

51 Brown KM, Geller DA: What is the learning curve for laparoscopic major hepatectomy? J Gastrointest Surg 2016;20:1065-1071.

52 Belghiti J, Regimbeau JM, Durand F, Kianmanesh AR, Dondero F, Terris B, et al: Resection of hepatocellular carcinoma: a European experience on 328 cases. Hepatogastroenterology 2002;49:41-46. 
53 Belli G, Fantini C, D’Agostino A, Cioffi L, Langella S, Russolillo N, et al: Laparoscopic versus open liver resection for hepatocellular carcinoma in patients with histologically proven cirrhosis: short- and middle-term results. Surg Endosc 2007;21:2004-2011.

54 Dagher I, Belli G, Fantini C, Laurent A, Tayar C, Lainas P, et al: Laparoscopic hepatectomy for hepatocellular carcinoma: a European experience. J Am Coll Surg 2010;211:16-23.

55 Lau H, Man K, Fan ST, Yu WC, Lo CM, Wong J: Evaluation of preoperative hepatic function in patients with hepatocellular carcinoma undergoing hepatectomy. Br J Surg 1997;84:1255-1259.

56 Fan ST: Liver functional reserve estimation: state of the art and relevance for local treatments: the Eastern perspective. J Hepatobiliary Pancreat Sci 2010;17:380-384.

57 Cai X, Liang X, Yu T, Liang Y, Jing R, Jiang W, et al: Liver cirrhosis grading Child-Pugh class B: a Goliath to challenge in laparoscopic liver resection? Prior experience and matched comparisons. Hepatobiliary Surg Nutr 2015;4:391-397.

58 Brytska N, Han HS, Shehta A, Yoon YS, Cho JY, Choi Y: Laparoscopic liver resection for hepatitis B and C virusrelated hepatocellular carcinoma in patients with Child B or C cirrhosis. Hepatobiliary Surg Nutr 2015;4: 373-378.

59 Yamanaka N, Okamoto E, Kuwata K, Tanaka N: A multiple regression equation for prediction of posthepatectomy liver failure. Ann Surg 1984;200:658-663.

60 Hemming AW, Scudamore CH, Shackleton CR, Pudek M, Erb SR: Indocyanine green clearance as a predictor of successful hepatic resection in cirrhotic patients. Am J Surg 1992;163:515-518.

61 Matsumata T, Kanematsu T, Yoshida Y, Furuta T, Yanaga K, Sugimachi K: The indocyanine green test enables prediction of postoperative complications after hepatic resection. World J Surg 1987;11:678-681.

62 Makuuchi M, Kosuge T, Takayama T, Yamazaki S, Kakazu T, Miyagawa S, et al: Surgery for small liver cancers. Semin Surg Oncol 1993;9:298-304.

63 Fan ST, Lai EC, Lo CM, Ng IO, Wong J: Hospital mortality of major hepatectomy for hepatocellular carcinoma associated with cirrhosis. Arch Surg 1995;130:198-203.

64 Miyagawa S, Makuuchi M, Kawasaki S, Kakazu T: Criteria for safe hepatic resection. Am J Surg 1995;169:589594.

65 Lam CM, Fan ST, Lo CM, Wong J: Major hepatectomy for hepatocellular carcinoma in patients with an unsatisfactory indocyanine green clearance test. Br J Surg 1999;86:1012-1017.

66 Cho JY, Han HS, Yoon YS, Shin SH: Experiences of laparoscopic liver resection including lesions in the posterosuperior segments of the liver. Surg Endosc 2008;22:2344-2349.

67 Sarpel U, Hefti MM, Wisnievsky JP, Roayaie S, Schwartz ME, Labow DM: Outcome for patients treated with laparoscopic versus open resection of hepatocellular carcinoma: case-matched analysis. Ann Surg Oncol 2009; 16:1572-1577.

68 Cherqui D: Laparoscopic liver resection. Br J Surg 2003;90:644-646.

69 Cho JY, Han HS, Yoon YS, Shin SH: Feasibility of laparoscopic liver resection for tumors located in the posterosuperior segments of the liver, with a special reference to overcoming current limitations on tumor location. Surgery 2008;144:32-38.

70 Ai JH, Li JW, Chen J, Bie P, Wang SG, Zheng SG: Feasibility and safety of laparoscopic liver resection for hepatocellular carcinoma with a tumor size of 5-10 cm. PLoS One 2013;8:e72328.

71 Kwon Y, Han HS, Yoon YS, Cho JY: Are large hepatocellular carcinomas still a contraindication for laparoscopic liver resection? J Laparoendosc Adv Surg Tech A 2015;25:98-102.

72 Shelat VG, Cipriani F, Basseres T, Armstrong TH, Takhar AS, Pearce NW, et al: Pure laparoscopic liver resection for large malignant tumors: does size matter? Ann Surg Oncol 2015;22:1288-1293.

73 Wakai T, Shirai Y, Sakata J, Kaneko K, Cruz PV, Akazawa K, et al: Anatomic resection independently improves long-term survival in patients with T1-T2 hepatocellular carcinoma. Ann Surg Oncol 2007;14:1356-1365.

74 Hasegawa K, Kokudo N, Imamura H, Matsuyama Y, Aoki T, Minagawa M, et al: Prognostic impact of anatomic resection for hepatocellular carcinoma. Ann Surg 2005;242:252-259.

75 Ueno S, Kubo F, Sakoda M, Hiwatashi K, Tateno T, Mataki Y, et al: Efficacy of anatomic resection vs nonanatomic resection for small nodular hepatocellular carcinoma based on gross classification. J Hepatobiliary Pancreat Surg 2008; 15:493-500.

76 Eguchi S, Kanematsu T, Arii S, Okazaki M, Okita K, Omata M, et al: Comparison of the outcomes between an anatomical subsegmentectomy and a non-anatomical minor hepatectomy for single hepatocellular carcinomas based on a Japanese nationwide survey. Surgery 2008;143:469-475.

77 Han HS, Cho JY, Yoon YS: Techniques for performing laparoscopic liver resection in various hepatic locations. J Hepatobiliary Pancreat Surg 2009;16:427-432.

78 Yamanaka N, Okamoto E, Toyosaka A, Mitunobu M, Fujihara S, Kato T, et al: Prognostic factors after hepatectomy for hepatocellular carcinomas. A univariate and multivariate analysis. Cancer 1990;65:1104-1110.

79 Ikeda K, Saitoh S, Tsubota A, Arase Y, Chayama K, Kumada H, et al: Risk factors for tumor recurrence and prognosis after curative resection of hepatocellular carcinoma. Cancer 1993;71:19-25.

80 Lau H, Fan ST, Ng IO, Wong J: Long term prognosis after hepatectomy for hepatocellular carcinoma: a survival analysis of 204 consecutive patients. Cancer 1998;83:2302-2311.

81 Song J, Wang Y, Ma K, Zheng S, Bie P, Xia F, et al: Laparoscopic hepatectomy versus radiofrequency ablation for minimally invasive treatment of single, small hepatocellular carcinomas. Surg Endosc 2016;30:4249_ 4257. 
82 Pompili M, Saviano A, de Matthaeis N, Cucchetti A, Ardito F, Federico B, et al: Long-term effectiveness of resection and radiofrequency ablation for single hepatocellular carcinoma $</=3 \mathrm{~cm}$. Results of a multicenter Italian survey. J Hepatol 2013;59:89-97.

83 Livraghi T, Meloni F, Di Stasi M, Rolle E, Solbiati L, Tinelli C, et al: Sustained complete response and complications rates after radiofrequency ablation of very early hepatocellular carcinoma in cirrhosis: Is resection still the treatment of choice? Hepatology 2008;47:82-89.

84 Kang TW, Kim JM, Rhim H, Lee MW, Kim YS, Lim HK, et al: Small hepatocellular carcinoma: radiofrequency ablation versus nonanatomic resection - propensity score analyses of long-term outcomes. Radiology 2015; 275:908-919.

85 Kim GA, Shim JH, Kim MJ, Kim SY, Won HJ, Shin YM, et al: Radiofrequency ablation as an alternative to hepatic resection for single small hepatocellular carcinomas. Br J Surg 2016;103:126-135.

86 Lei JY, Wang WT, Yan LN, Wen TF, Li B: Radiofrequency ablation versus surgical resection for small unifocal hepatocellular carcinomas. Medicine (Baltimore) 2014;93:e271.

87 Harada N, Shirabe K, Maeda T, Kayashima H, Takaki S, Maehara Y: Comparison of the outcomes of patients with hepatocellular carcinoma and portal hypertension after liver resection versus radiofrequency ablation. World J Surg 2016;40:1709-1719.

88 Cucchetti A, Piscaglia F, Cescon M, Ercolani G, Pinna AD: Systematic review of surgical resection vs radiofrequency ablation for hepatocellular carcinoma. World J Gastroenterol 2013;19:4106-4118.

89 Harada N, Maeda T, Yoshizumi T, Ikeda T, Kayashima H, Ikegami T, et al: Laparoscopic liver resection is a feasible treatment for patients with hepatocellular carcinoma and portal hypertension. Anticancer Res 2016; 36:3489-3497.

90 Arii S, Tanaka J, Yamazoe Y, Minematsu S, Morino T, Fujita K, et al: Predictive factors for intrahepatic recurrence of hepatocellular carcinoma after partial hepatectomy. Cancer 1992;69:913-919.

91 Imamura H, Matsuyama Y, Tanaka E, Ohkubo T, Hasegawa K, Miyagawa S, et al: Risk factors contributing to early and late phase intrahepatic recurrence of hepatocellular carcinoma after hepatectomy. J Hepatol 2003; 38:200-207.

92 Shirabe K, Kajiyama K, Harimoto N, Masumoto H, Fukuya T, Ooya M, et al: Prognosis of hepatocellular carcinoma accompanied by microscopic portal vein invasion. World J Gastroenterol 2009;15:2632-2637.

93 Chok KS, Cheung TT, Chan SC, Poon RT, Fan ST, Lo CM: Surgical outcomes in hepatocellular carcinoma patients with portal vein tumor thrombosis. World J Surg 2014;38:490-496.

94 Kokudo T, Hasegawa K, Matsuyama Y, Takayama T, Izumi N, Kadoya M, et al: Survival benefit of liver resection for hepatocellular carcinoma associated with portal vein invasion. J Hepatol 2016;65:938-943.

95 Nakahira S, Takeda Y, Katsura Y, Kato T, Hatanaka N, Tamura S: Laparoscopic left hepatectomy with tumor thrombectomy in patients with hepatocellular carcinoma concomitant with advanced portal vein tumor thrombus. Surg Endosc 2014;28:3505.

96 Ban D, Tanabe M, Ito H, Otsuka Y, Nitta H, Abe Y, et al: A novel difficulty scoring system for laparoscopic liver resection. J Hepatobiliary Pancreat Sci 2014;21:745-753.

97 Im C, Cho JY, Han HS, Yoon YS, Choi Y, Jang JY, et al: Validation of difficulty scoring system for laparoscopic liver resection in patients who underwent laparoscopic left lateral sectionectomy. Surg Endosc 2017;31:430-436.

98 Ratti F, D’Alessandro V, Cipriani F, Giannone F, Catena M, Aldrighetti L: Influence of body habitus on feasibility and outcome of laparoscopic liver resections: a prospective study. J Hepatobiliary Pancreat Sci 2016;23:373381.

99 Tanaka S, Kubo S, Kanazawa A, Takeda Y, Hirokawa F, Nitta H, et al: Validation of a difficulty scoring system for laparoscopic liver resection: a multicenter analysis by the Endoscopic Liver Surgery Study Group in Japan. J Am Coll Surg 2017;225:249-258.

100 Mutter D, Dallemagne B, Bailey C, Soler L, Marescaux J: 3D virtual reality and selective vascular control for laparoscopic left hepatic lobectomy. Surg Endosc 2009;23:432-435.

101 Velayutham V, Fuks D, Nomi T, Kawaguchi Y, Gayet B: 3D visualization reduces operating time when compared to high-definition 2D in laparoscopic liver resection: a case-matched study. Surg Endosc 2016;30:147-153.

102 Buia A, Stockhausen F, Filmann N, Hanisch E: 3D vs. 2D imaging in laparoscopic surgery-an advantage? Results of standardised black box training in laparoscopic surgery. Langenbecks Arch Surg 2017;402:167-171.

103 Satou S, Ishizawa T, Masuda K, Kaneko J, Aoki T, Sakamoto Y, et al: Indocyanine green fluorescent imaging for detecting extrahepatic metastasis of hepatocellular carcinoma. J Gastroenterol 2013;48:1136-1143.

104 Kudo H, Ishizawa T, Tani K, Harada N, Ichida A, Shimizu A, et al: Visualization of subcapsular hepatic malignancy by indocyanine-green fluorescence imaging during laparoscopic hepatectomy. Surg Endosc 2014;28: 2504-2508.

105 Zhang YM, Shi R, Hou JC, Liu ZR, Cui ZL, Li Y, et al: Liver tumor boundaries identified intraoperatively using real-time indocyanine green fluorescence imaging. J Cancer Res Clin Oncol 2017;143:51-58.

106 Aoki T, Yasuda D, Shimizu Y, Odaira M, Niiya T, Kusano T, et al: Image-guided liver mapping using fluorescence navigation system with indocyanine green for anatomical hepatic resection. World J Surg 2008;32:17631767.

107 Ishizawa T, Zuker NB, Kokudo N, Gayet B: Positive and negative staining of hepatic segments by use of fluorescent imaging techniques during laparoscopic hepatectomy. Arch Surg 2012;147:393-394.

108 Ishizawa T, Gumbs AA, Kokudo N, Gayet B: Laparoscopic segmentectomy of the liver: from segment I to VIII. Ann Surg 2012;256:959-964. 
109 Inoue Y, Arita J, Sakamoto T, Ono Y, Takahashi M, Takahashi Y, et al: Anatomical liver resections guided by 3-dimensional parenchymal staining using fusion indocyanine green fluorescence imaging. Ann Surg 2015; 262:105-111.

110 Miyata A, Ishizawa T, Tani K, Shimizu A, Kaneko J, Aoki T, et al: Reappraisal of a dye-staining technique for anatomic hepatectomy by the concomitant use of indocyanine green fluorescence imaging. J Am Coll Surg 2015;221:e27-e36.

111 Ishizawa T, Fukushima N, Shibahara J, Masuda K, Tamura S, Aoki T, et al: Real-time identification of liver cancers by using indocyanine green fluorescent imaging. Cancer 2009;115:2491-2504.

112 Shibasaki Y, Sakaguchi T, Hiraide T, Morita Y, Suzuki A, Baba S, et al: Expression of indocyanine green-related transporters in hepatocellular carcinoma. J Surg Res 2015;193:567-576.

113 Tsung A, Geller DA, Sukato DC, Sabbaghian S, Tohme S, Steel J, et al: Robotic versus laparoscopic hepatectomy: a matched comparison. Ann Surg 2014;259:549-555.

114 Lai EC, Tang CN: Long-term survival analysis of robotic versus conventional laparoscopic hepatectomy for hepatocellular carcinoma: a comparative study. Surg Laparosc Endosc Percutan Tech 2016;26:162-166.

115 Lee KF, Cheung YS, Chong CC, Wong J, Fong AK, Lai PB: Laparoscopic and robotic hepatectomy: experience from a single centre. ANZ J Surg 2016;86:122-126.

116 Croner RS, Perrakis A, Hohenberger W, Brunner M: Robotic liver surgery for minor hepatic resections: a comparison with laparoscopic and open standard procedures. Langenbecks Arch Surg 2016;401:707-714.

117 Montalti R, Scuderi V, Patriti A, Vivarelli M, Troisi RI: Robotic versus laparoscopic resections of posterosuperior segments of the liver: a propensity score-matched comparison. Surg Endosc 2016;30:1004-1013.

118 Briceno J, Naranjo A, Ciria R, Diaz-Nieto R, Sanchez-Hidalgo JM, Luque A, et al: A prospective study of the efficacy of clinical application of a new carrier-bound fibrin sealant after liver resection. Arch Surg 2010;145: $482-488$.

119 Koea JB, Batiller J, Patel B, Shen J, Hammond J, Hart J, et al: A phase III, randomized, controlled, superiority trial evaluating the fibrin pad versus standard of care in controlling parenchymal bleeding during elective hepatic surgery. HPB (Oxford) 2013;15:61-70.

120 Figueras J, Llado L, Miro M, Ramos E, Torras J, Fabregat J, et al: Application of fibrin glue sealant after hepatectomy does not seem justified: results of a randomized study in 300 patients. Ann Surg 2007;245:536-542.

121 de Boer MT, Klaase JM, Verhoef C, van Dam RM, van Gulik TM, Molenaar IQ, et al: Fibrin sealant for prevention of resection surface-related complications after liver resection: a randomized controlled trial. Ann Surg 2012; 256:229-234.

122 Kobayashi S, Takeda Y, Nakahira S, Tsujie M, Shimizu J, Miyamoto A, et al: Fibrin sealant with polyglycolic acid felt vs fibrinogen-based collagen fleece at the liver cut surface for prevention of postoperative bile leakage and hemorrhage: a prospective, randomized, controlled study. J Am Coll Surg 2016;222:59-64. 